\title{
Spiritual care may impact mental health and medication adherence in $\mathrm{HIV}+$ populations
}

This article was published in the following Dove Press journal:

HIVIAIDS - Research and Palliative Care

28 April 2017

Number of times this article has been viewed

\author{
Valerie $U$ Ojil-3 \\ Leslie C Hung ${ }^{3}$ \\ Reza Abbasgholizadeh 1,4 \\ Flora Terrell Hamilton ${ }^{5}$ \\ E James Essien ${ }^{6}$ \\ Evaristus Nwulia ${ }^{7}$ \\ 'Lifefountain Center Ministries Inc, \\ Houston, TX, USA; ${ }^{2}$ Feik School \\ of Pharmacy, University of the \\ Incarnate Word, San Antonio, TX, \\ USA; ' University of Texas, College \\ of Pharmacy, Austin, TX, USA; \\ ${ }^{4}$ University of Houston, Houston, \\ TX, USA; ${ }^{5}$ Administration, Family \\ \& Medical Counseling Service, Inc. \\ (FMCS), Washington, DC, USA; \\ 'University of Houston Institute \\ for Community Health, Houston, \\ TX, USA; 'Psychiatry, Howard \\ University Translational Neuroscience \\ Laboratory, Washington, DC, USA
}

Correspondence: Valerie U Oji

Lifefountain Center Ministries Inc, 3880

Greenhouse Road 402, Houston, TX

77084, USA

Tel +l 28I 492 I335

Email medgal8@gmail.com
Objective: To explore a potential role for spirituality in medication-related needs assessment for integrated care in chronically ill populations.

Method: A systematic literature review was conducted to explore the impact of faith beliefs on health and/or medication adherence in individuals with depression and/or HIV+/AIDS. Retrospective electronic medical record review of adult HIV+ patients of an urban primary care clinic with integrated mental health services was conducted, with Substance Abuse and Mental Illness Symptoms Screener (SAMISS), major depressive disorder (MDD) incidence over the preceding year, and history of contact with a spiritual advisor. A convenience sample was interviewed to qualitatively assess potential medication therapy management needs and medication-related problems. Another sample was examined utilizing the Daily Spiritual Experience Scale.

Results: The literature reports positive influence on health behaviors, coping and outcomes; and poor medication adherence and treatment decisions due to patient passivity or resistance. Spiritual advisor contact (not limited to a specific religion) was significantly associated with MDD absence $(1.7 \%$ vs. $15.3 \%, P<0.005)$ and inversely related to SAMISS, depression, and poor health behaviors. Patient interviews reflected significance of faith in terms of insight and acceptance of illness, the role or need for medications, coping, and medication adherence. An illustrative model was designed based on the literature and data collection.

Conclusion: Spiritual assessment may help identify positive or negative influence on health. Spiritual interventions could be beneficial in promoting adherence and positive health outcomes. Further research is recommended.

Keywords: HIV+/AIDS, mental illness, depression, spirituality and health, African Americans

\section{Introduction}

"Faith" includes a sense of connection to something bigger than ourselves, and it typically involves an innate search for meaning, purpose, and significance. Spirituality represents a path the person takes in order to connect with his/her faith, as evidenced by public practices (e.g., church attendance), prayer, religious commitment, coping, and experiences. ${ }^{1,2}$ Religion provides an organized system of practices and beliefs in which people engage, and it serves as a platform for the expression of spirituality. ${ }^{3}$ Spirituality, described as one's non-physical essence or that aspect of individual beliefs, core values, faith systems, and/or practices by which life meaning is assigned, ${ }^{1}$ is reported to impact health. In the context of our study, these terms (spirituality, religion, and faith) are used interchangeably to represent a broad belief in a higher power or source, often outside of an individual's control; ${ }^{2}$ although in fact individual spirituality may exist apart from religious practice or faith traditions. 
Integrated care of physical and mental health conditions has been increasingly recommended to improve patient outcomes; ${ }^{4}$ this may be of particular value where there are comorbid chronic conditions. Comorbidity of HIV+ and depression reportedly could impact health outcomes with clinical, economic, and/or humanistic consequences. Depression rates are higher among HIV+ individuals than the wider US population; higher among HIV+ women, minorities, and individuals with co-existing substance use. ${ }^{5-11}$ Depression has been associated with poorer CD-4 T-cell counts, higher HIV+ viral loads, lower antiretroviral therapy (ART) adherence, poorer prognosis, and higher mortality. ${ }^{12-15}$ These health outcomes could be more profound in regions with inordinately higher disease prevalence and vulnerable populations. Urban, low-income African Americans (AAs) living in Washington DC are the population of interest in this study and are disproportionately vulnerable to the HIV+/AIDS epidemic. ${ }^{16}$ According to the DC Department of Health Annual Epidemiology and Surveillance Report, although AAs account for $48.6 \%$ of DC residents, they account for $75 \%$ of individuals living with HIV+ in DC. AA women account for $92.6 \%$ of women living with HIV+ in DC. ${ }^{17}$

Spirituality and faith traditions have been reported as significant to many individuals and could thus be a point of health care intervention. In one multistate study of primary care patients, a substantial proportion of surveyed patients expressed that physicians should be aware of spiritual beliefs or desire for spiritual interaction during health care visits. ${ }^{18}$ Many studies have linked depression to spirituality. It has been shown that greater religiosity may contribute to development of resilience in certain high-risk individuals having a depressed parent. ${ }^{19}$ In another study, it was shown that depressive episodes often lead to a search for spirituality, which may be helpful in decreasing depression or becoming less vulnerable to relapsing. ${ }^{20}$ In addition, spirituality was found to be one of the significant factors decreasing depression in patients with alcohol use disorder. ${ }^{20}$ Furthermore, in a neuroanatomical study, importance of religion or spirituality was associated with thicker cortices in the left and right parietal and occipital regions, the mesial frontal lobe of the right hemisphere, and the cuneus and precuneus in the left hemisphere. This thicker cortex may assist individuals with high familial risk of major depression to recover from complications of depressive disorders. ${ }^{21}$

Spirituality and faith play a role in individuals of every ethnicity and background, but may impact certain populations more than others. In one survey conducted in 2001, AAs were more likely to mention prayer as their most important source of influence in their HIV+ medication decisions compared with Caucasians..$^{22}$ For many patients, religious and spiritual beliefs are at the core of their identity and their response to sickness. ${ }^{23}$ Incorporating spiritual care into a patient's chronic therapy plan, especially considering our study population, could be helpful to promote better adherence and ultimately better health outcomes.

This study sought to explore the literature regarding the relationship between spirituality and medication adherence, particularly in depression and/or HIV+/AIDS; investigate health outcomes; and identify medication-related needs including spiritual care among HIV+ individuals at a community-based clinic in Washington DC, which serves predominantly low-income AAs.

\section{Methods}

Institutional review board (IRB) approval was obtained for all aspects of the project from IntegReview and Howard University IRBs. Informed consent was obtained for study participant interviews and medical record reviews. An illustrative flow of methods is depicted in Figure 1.

\section{Literature review}

In our systematic review, three databases (PsycARTICLES, MEDLINE, and CINAHL Plus) were utilized to conduct literature searches for articles that highlighted the potential impact of faith and spirituality on medication adherence in patients who are undergoing long-term therapy. These peerreviewed studies were published between the years 1986 and 2015. Keywords such as "Impact" OR "Influence" OR "Effects" AND "spirituality" OR "faith" OR "religion" AND "depression" OR "HIV+" OR "AIDS" AND "medication" OR "medication adherence" were used for our searches. A total of 86 non-duplicate articles emerged from our searches.

After reviewing each abstract, we narrowed it down to 48 articles that were related to spirituality/religion/faith affecting some form of health-related outcome in chronically ill patients. We further narrowed down from the 48 articles, 33 that specifically related medication adherence to the HIV+/ AIDS and/or the depression population.

\section{Medical record review}

A retrospective review of adult HIV+ patients of an urban primary care clinic with integrated physical and mental health services had been conducted by means of electronic medical record review, Substance Abuse and Mental Illness Symptoms Screener (SAMISS), major depressive disorder (MDD) incidence over the preceding year, and history of 


\section{Literature review \\ (Search through PsycARTICLES, MEDLINE, and CINAHL Plus databases) \\ Impact OR Influence OR Effects AND Spirituality OR Faith OR religion AND depression OR HIV OR AIDS AND medication adherence \\ 86 articles >>> 48 > > 33: spirituality, medication adherence in HIVIAIDS and/or depression}

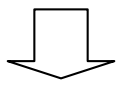

Medical record review

(Review of clinic electronic medical records; $n=147$ )

Depression screening, adherence, health behaviors, spirituality screening

SAMISS, medical record documentation of depression diagnosis or antidepressant use, patient selfreport of preceding 1-year depressive symptoms, patient self-report \% ART adherence, drinking and drinking discontinuation, prescription and illegal drug use, preceding 1-year spiritual advisor contact, DSES

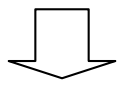

Patient comprehensive medication review interviews

Medication-related problem identification $(n=18)$

Participant and staff interviews on clinic medication use processes

Emergent themes on adherence and medication use identified

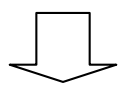

Conceptual illustration: spirituality, adherence, and health

Synthesis: spirituality and health literature, literature review, investigator-published work, DSES, interviews, Proposed spirituality and health associations with potential impact of faith-treatment incongruence

Figure I Methods.

Abbreviations: ART, antiretroviral therapy; DSES, Daily Spiritual Experience Scale.

contact with a spiritual advisor. This component of the clinic data emerges from a 3-year project "Adaptation of Effective Depression Screening Tool for HIV+ African American Urban DC Residents" aimed at the development of culturally adapted interventions and improved treatment adherence in community-based care for an urban, minority population. The clinic provides behavioral health case management and support groups, including spirituality group. During early phases of the project, it was noted from multiple staff mental health specialist interviews that patients would often deny experiencing depressive symptoms during their routine medical visits, were generally reluctant to discuss psychiatric symptoms, but were much more open about mental health issues during the clinic's spirituality group.

The clinic population comprises primarily adult, urban, African Americans. The SAMISS was used as a part of patient intake by clinical personnel trained in its administration. The SAMISS provides comprehensive evaluation of mental health and substance abuse conditions in HIV+ patients. It is a 16-question screening tool that takes under 15 minutes to administer. ${ }^{24}$ Patients are screened for HIV+ status, sociodemographic, behavioral, and medical information that are inputted into the electronic medical record. Patient CD-4+ counts are documented from blood draws collected on day of intake and follow-up visits.

\section{Depression screening}

The retrospective medical record review was conducted for $158 \mathrm{HIV}+$ clinic patients to examine depression diagnosis over a 2-year period. Patients had been interviewed as to whether they had experienced, within the preceding year, a diagnosis of depression or any depressive symptoms lasting 2 or more weeks. All participants were classified as MDD who gave an affirmative response. The MDD classifications were also verified or supported from the medical records by documented physician diagnosis or prescribed antidepressants.

\section{Adherence, health behaviors, and spirituality screening}

ART adherence was evaluated for this population at intake by asking what percentage of the time they took their treatments as prescribed. Self-reported ART adherence classification was as follows: $\geq 80 \%$ - adequate; $\leq 80$ - inadequate. Problem drinking was determined from SAMISS with the following classification: $>4$ drinks per episode was categorized as heavy. Difficulty with drinking discontinuation; social problems related to drinking; and prescription and illegal drug use over the preceding year were also noted. Patients also self-reported whether they had received contact of any form with a spiritual advisor within the preceding year. A spiritual advisor was someone recognized by the individual 
as having spiritual training or leadership significant to that individual's beliefs to provide spiritual advice, support, or counseling. A second sample was examined using the Daily Spiritual Experience Scale (DSES), a 16-item self-report measure of spiritual experience, for items reflecting strongly in score and/or prevalence.

\section{Patient comprehensive medication review (CMR) interviews}

At a follow-up focus group, $18 \mathrm{HIV}+$ individuals receiving services at the clinic were interviewed to qualitatively assess potential medication therapy management (MTM) needs and medication-related problems (MRPs). Semistructured interviews were conducted by the principal investigator to perform a CMR and identify MRPs as a core component of MTM. Patients were asked to name their medications and what they had been prescribed for. MRPs were categorized, patient responses to open-ended questions documented, and interview notes reviewed for keyword coding and emergent themes. Participants and staff were interviewed to gain understanding of care delivery processes with respect to medication use.

\section{Results}

Only three studies examined medication adherence in $\mathrm{HIV+/}$ AIDS patients suffering from depression and in relation to spiritual involvement. ${ }^{25-27}$ One publication examined women suffering from substance abuse and their adherence to ART. ${ }^{28}$

Depression is a common comorbidity for patients suffering from an HIV+/AIDS diagnosis. ${ }^{25}$ In a 2013 study, Dalmida et al. found that out of 292 patients living with HIV+/AIDS, $56.9 \%$ reported depressive symptoms. ${ }^{25}$ These patients with concurrent depression report significantly poorer health outcomes, including lower adherence to ART, lower CD-4+ cell counts, and generally lower health-related quality of life. They also found that the odds of being depressed were significantly associated with lack of religious coping. ${ }^{25}$ In a study on adolescents between 14 and 22 years of age with HIV+/AIDS, they found that subjects with lower depression scores (using the Beck Depression Inventory-II) had excellent adherence compared to those with higher depression scores. ${ }^{26}$ The third study in 2007 that involved HIV+ women with depression in the Southeastern US concluded that coping by spiritual activities was negatively correlated with missed medications $(P=0.005)$, along with availability of social support, coping by positive thinking, coping by managing HIV+ disease, and coping by focusing on the present. ${ }^{27}$

Another population we wanted to examine was the HIV+ patients who had substance abuse disorders. Substance abuse has been linked in the past with poor adherence to ART. ${ }^{29,30}$ One study focused specifically on adherence factors in women on highly active ART who had concomitant substance abuse issues. Most women in the study admitted that abuse of illicit drugs and/or alcohol was the most important and difficult barrier to taking medications. Many women claimed that reliance on spirituality, God, and religion helped them take their medications. ${ }^{28}$

In the majority of the 33 studies, spirituality had a positive influence on health behaviors and outcomes. Faith is often correlated with stronger social support, ${ }^{4}$ better coping skills, ${ }^{25,27-38}$ and generally higher health-related quality of life. ${ }^{25,39}$ In the Park and Nachman ${ }^{26}$ study mentioned above with adolescents, they also saw that subjects with excellent adherence had significantly higher religious belief scores compared to those who had poor adherence $(3.46 \pm 0.46 \mathrm{vs}$. $2.34 \pm 0.69, P<0.05) .{ }^{26}$ Similarly, a study conducted with HIV+/AIDS patients in South Florida in 2009 demonstrated that "the presence vs. absence of the belief 'spirituality helps coping with side effects' was significantly associated with better adherence and fewer symptoms". Out of the 79 patients included in this study, about half of the participants $(38 / 79 ; 48 \%)$ reported spiritual/mind-body beliefs related to treatment adherence. ${ }^{33}$ In a study in 2006, they focused on African American and Puerto Rican patients in the US and found that "social support predicted lower levels of negative affect and greater spirituality, which in turn predicted selfefficacy to adhere". ${ }^{40}$

Adversely, a few studies found some levels of faith in God could be damaging to medication adherence as patients start to take a passive role in their own health care..$^{33,34,41,42}$ In the same 2003 study, ${ }^{33}$ spirituality was noted to adversely affect treatment decisions, with participants who believed that their health was controlled by God/Higher Power being 4.75 times more likely to not take antiretrovirals compared with those who did not express this control belief $(P=0.032){ }^{33}$ Providers may need to use caution because some patients seek more strength in God/religion than in themselves. This could manifest as a strength or in contrast result in decreased adherence to therapy as they start relying on an outside source of control without applying inner strength and perseverance. ${ }^{34-36}$ Patients may also present with a view of God that asserts that their diagnosis is a "punishment from God" or "God's will". ${ }^{37,43,44}$ A study in 2011 showed that a view of God as harsh/judgmental/punishing predicted faster disease progression over 4 years in HIV+ individuals. ${ }^{4}{ }^{4}$

Most of the studies reviewed were conducted in the US, but we also evaluated some studies that took place in 
Africa, ${ }^{37,38,40,42,45-49}$ Asia, ${ }^{27,50}$ the Middle-East, ${ }^{51}$ and South America. ${ }^{52}$ These regions are associated with a high prevalence of HIV+/AIDS, and oftentimes these individuals face more barriers to adherence in the form of social stigma/ shame, ${ }^{37,38,42,46,47,52}$ medication access, ${ }^{37,38,42,47,52}$ and lack of education on antiretrovirals. ${ }^{42,46,47}$ Social stigma presented as a barrier to medication adherence because many patients feared disclosing their HIV+ status to their family, friends, and community. Patients who concealed their illness may not feel comfortable taking their medications in front of others or going to pick up their medications from clinics. Medication access also proved to be a problem in these regions. Clinics were often under-resourced to deal with the volume of patients, which led to delays on clinic days and limited ART availability to desperate individuals. ${ }^{37}$ Increased visits to clinics also exposed patients to more embarrassment and stigma. False beliefs and lack of education about ART also resulted in less medication adherence. Patients may not be well informed about the consequences of non-adherence, the efficacy of therapy, and the potential for side effects. ${ }^{42}$ They tend to rely heavily on complementary alternative therapies in the form of herbs, holy water, and guidance from spiritual leaders. ${ }^{37,38,42,46,48}$

\section{Retrospective medical record review}

The SAMISS provides comprehensive evaluation of mental health and substance abuse conditions in HIV+ patients. It is a 16-question screening tool that takes under 15 minutes to administer. ${ }^{24}$ SAMISS data for 147 patients were reviewed, $99 \%$ of whom were adult AAs. Contact with a spiritual advisor over the preceding year was significantly associated with the absence of MDD $(1.7 \%$ vs. $15.3 \%, P<0.005)$. Figure 2 depicts ART adherence data for patients with and without an MDD diagnosis. The groups with MDD receiving treatment

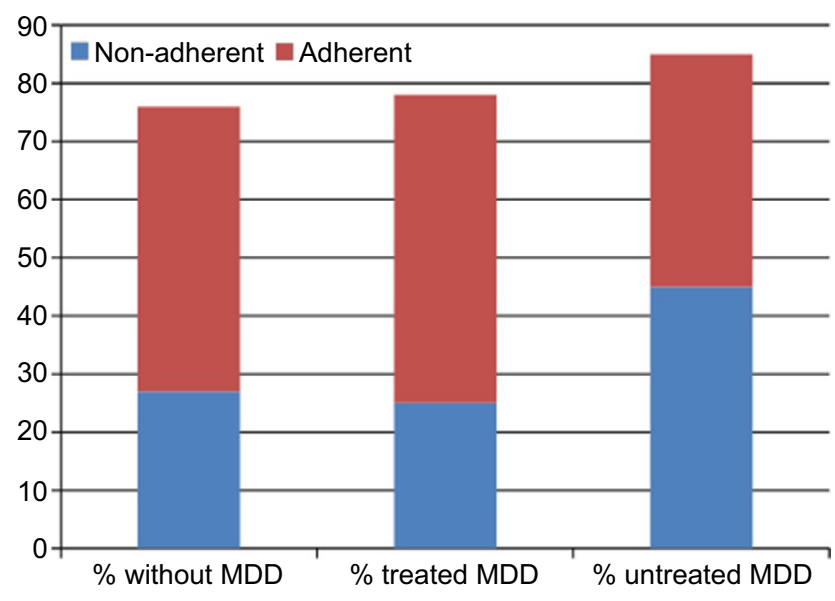

Figure 2 ART adherence features of study patients with and without MDD. Abbreviations: ART, antiretroviral therapy; MDD, major depressive disorder. and without MDD were comparable in the levels of ART adherence (53\% vs. $48 \%$, respectively) and non-adherence ( $25 \%$ vs. $27 \%$ ), while the level of ART non-adherence in individuals with untreated MDD was $45 \%(P=0.51)$. Without MDD and treated MDD patients also had more favorable patterns of problem drinking absence (73\% vs. 55\%) than individuals with untreated $\operatorname{MDD}(45 \% P=0.02)$. The number of patients without MDD, treated MDD, and untreated MDD was 89,38 , and 20 , respectively. No significant differences were found with gender, age, education, income, or substance abuse patterns among the participants across MDD groups. Figure 3 illustrates specific DSES items that scored high among participants; specifically forgiveness, gratefulness, positive emotions, and existential well-being. The study population was found to have strong spiritual experiences in areas of belief, relation and attachment or connection, positive emotions, well-being, and altruism. Statistical analysis was conducted using STATA, version 12.

\section{Patient CMR interviews}

The majority of patients interviewed were unable to name all of their medications; however, several were able to recall with prompting or assistance. Few already had a printed medication list, typically given to a patient during a CMR and updated with routine MTM visits. All participants except one preferred to use a local independent pharmacy for their prescriptions; one used a mail order pharmacy with the medications delivered to their primary care physician's (PCP's) office. There was no prior experience with pharmacist provision of MTM. All medication questions, should they arise, were reportedly directed to their PCP's office. Number of medications on patients' regimens ranged from 2-22; patients were HIV+ and had at least one psychiatric diagnosis. Potential MRPs identified included insight or acceptance of their illness, non-adherence, medication costs, untreated symptoms, and unwanted side effects. Statement excerpt examples suggesting some influence of spirituality include "I don't claim any illness; by his stripes I'm healed [...]"; "My healing is my testimony"; "I'm not sick, I'm blessed"; the majority of participants made some reference to their faith as a source of strength and coping. There were complaints of having too many medications prescribed, complaints such as unresolved insomnia, fatigue, pain or concerns about medication toxicity. One patient reported taking "medication holidays" to minimize side effects or adverse reaction risk; several others reported discontinuing and restarting medications for cost reasons. Emergent themes were spirituality professed as significant; spirituality could 


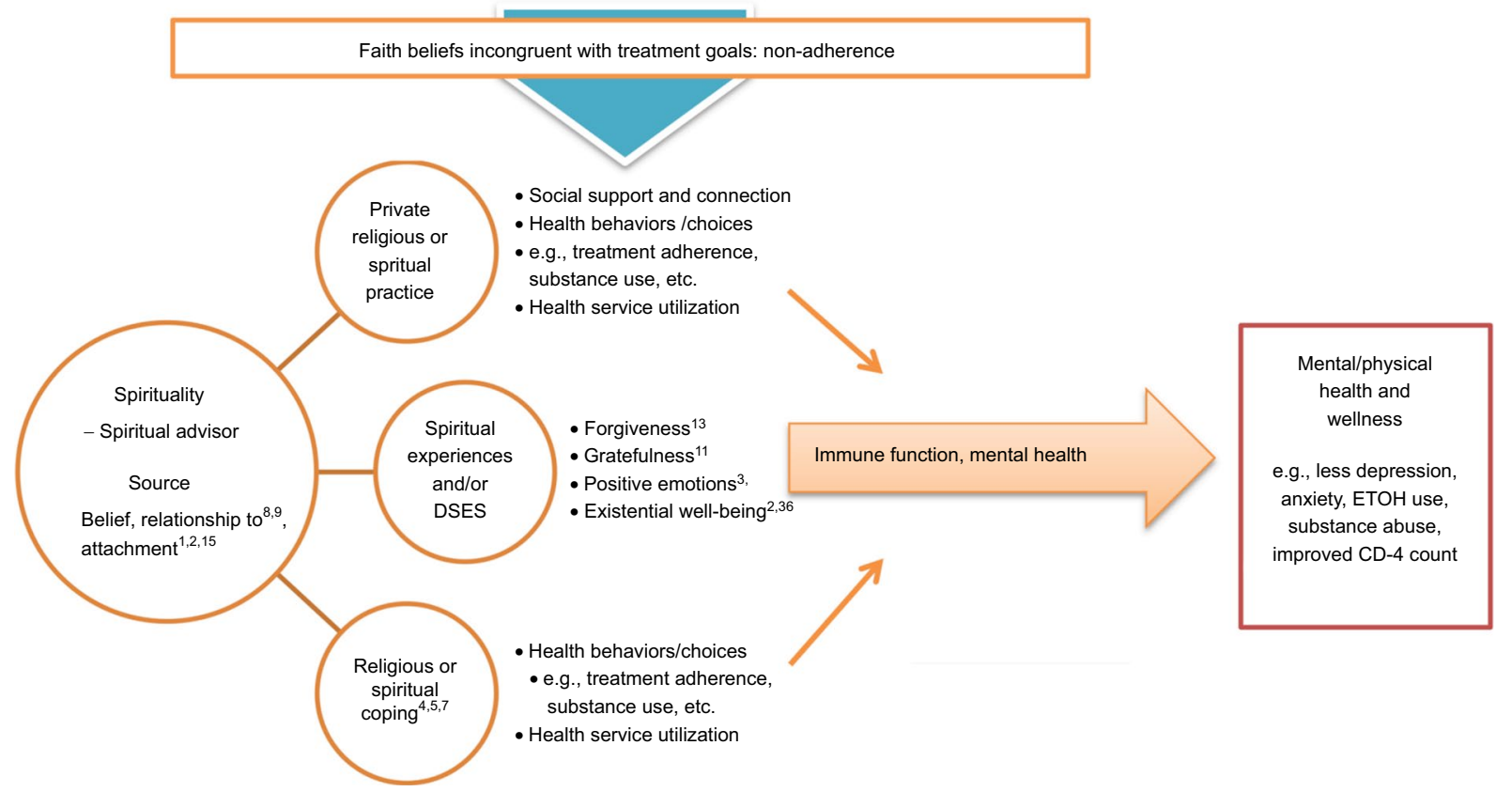

Figure 3 Spirituality and health.

Abbreviations: DSES, Daily Spiritual Experience Scale; ETOH, ethyl alcohol.

impact insight, coping, and perceptions of need for treatment or adherence; multiple factors such as side effects, attitudes to medications, and medication costs could also influence adherence; existing health services could benefit by incorporation of medication-related targeted interventions.

\section{Discussion}

This project utilized a mixed-methods approach to explore the impact of spirituality and its application to chronic integrated care, with a focus on depression and HIV+/AIDS.

\section{Spirituality and health}

A combination of enhanced depression screening and recognition, coping with illness, stress and trauma, health choices and behaviors such as medication adherence, reduced substance seeking and use, as well as effects on immunologic, physiological, and mental function, may facilitate improved outcomes. ${ }^{43-45,53-56}$ Spirituality has been suggested to have a positive impact on behaviors, coping, sense of well-being, self-esteem, self-care, depression, anxiety, and substance abuse $^{43,53-56}$ and is associated with lower suicide rates. ${ }^{56,57}$ A growing body of literature supports a positive association between spiritual attitudes ${ }^{58}$ beliefs and practices ${ }^{59}$ and mental health; HIV+ outcomes; ${ }^{43,60}$ as well as in mind-body mechanisms and immunologic processes involved in both $\mathrm{HIV}+$ and depression. ${ }^{56}$

Through our literature review, it was evident that spirituality plays a role in adherence related to antiretrovirals. Most reports showed a positive correlation between spirituality and medication adherence, with only a few demonstrating faith in God that is incompatible with illness acceptance and treatment resulting in passivity and resistance. Spirituality could help provide foundational support in managing therapies, and in turn resulting in greater adherence as patients learn to cope and find hope. Spirituality could perhaps serve as a bridge to overcome barriers to care such as mistrust of the health care system and stigma associated with chronic illness and their specific medical conditions in settings such as the study population, where there was more comfort speaking about psychiatric symptoms in spirituality group. Some form of assessment of individual faith-treatment congruence could be beneficial to gauge if there are attitudes that would work in support of or against treatment and medication adherence.

The majority of the studies identified from the literature review assessed adherence in the HIV+/AIDS population, not as many studied the depression population or those with chronic mental illness. This is most likely due to the wellknown long-term commitment of ART and the importance of adherence in preventing viral resistance. ${ }^{61}$ Patients who are $\mathrm{HIV}+$ and have a chronic mental disorder such as depression, although vulnerable to poorer health outcomes, could benefit from services that adequately detect and treat the mental disorder as well as facilitate spiritual or religious coping. Such coping, congruent with one's perceptions or insight into illness and treatment, may provide social support and improve medication adherence. Spiritual or religious coping could also help to overcome barriers to adherence such as substance abuse and facilitate positive health behaviors. On 
the other hand, providers should consider taking into account what strategies could be employed to identify and address faith-treatment incongruence and any consequent adverse health behaviors or treatment decisions. Processes to promote patient illness and medication education, enhance medication access, and perhaps discreet prescription delivery, individual privacy, and ways to overcome stigma and shame could be beneficial. Spirituality group or individual CMR sessions could be a forum that some consider safe to reveal and discuss faith-treatment incongruence, negative consequences of treatment non-adherence, and in an integrated care setting, psychiatric consultant referral.

The demographics in most of the HIV+/AIDS studies reviewed showed a disproportionate number of AAs compared to other ethnic populations. Minority populations both in the US and from other countries were found to rely on spirituality more so than Caucasian populations. ${ }^{22}$ More studies can be conducted to investigate this particular patient population and gain a better understanding of their motivations and obstacles.

Figure 3 gives a proposed illustration of study population spirituality and health. Private practices, spiritual experiences, and spiritual or religious coping can all potentially impact behaviors that could work along with or against treatment adherence and outcomes. ${ }^{43-45,55-57,60}$ Spiritual experiences might help to evaluate positive experiences by which spirituality may contribute to health outcomes. Faith beliefs that do not produce these positive experiences or compatible behaviors could result in poor or non-adherence and suboptimal outcomes. In a patient with adversely impacting spiritual beliefs, health behaviors and non-adherence could produce a picture similar to untreated MDD in HIV+ depressed individuals (i.e., Figure 2). Individuals without depression (without MDD) and treated depression (treated MDD) had similar proportions of individuals who were nonadherent to ART medications when compared to each other, while those with untreated MDD had a higher proportion of non-adherence.

The positive association between spiritual advisor and MDD absence could suggest spirituality is protective against MDD; although the impact of a spiritual advisor has not been fully elucidated. Level of spirituality and connectedness with a higher being or cause could be reflected in contact with the advisor; or the advisor provides support and influence that could help with positive emotions or impact behavior. More research would be necessary to investigate any possible association. The study did not include additional information on spiritual advisor contacts after initial intake; continuing impact, if any, is unknown and association with depression outcomes could not be established. This could also possibly be accounted for in the DSES, considered to have scale items leaning more towards mental health assessment than spirituality (personal communication, $\mathrm{H}$ Koenig, November 2014).Lack of documented continuing spiritual advisor contact; faith beliefs driving incompatible or counterproductive behaviors to patient's own health care and incompatible behaviors that remain unaddressed by both health providers and spiritual advisors could contribute to nonadherence or poor outcomes. Furthermore, there could be other contributory factors to treatment non-adherence, which were not identified; spirituality assessment and CMR as a routine part of care could be beneficial to identify these.

Overall, Figure 3 is intended to illustrate an opportunity for positive impact of spirituality or religion on physical and mental health. The DSES measures ordinary, or daily, spiritual experiences as an everyday part of the individual's life. ${ }^{62}$ Figure 3 includes specific DSES items that scored high in the study population, with specific corresponding DSES item number(s) highlighted in superscript. Spirituality could be reflected in belief, relationship to, and connection with a source. Contact with a spiritual advisor could result from individual spirituality or religious source or could be a part of spiritual or religious practices, experiences, or coping. Health behaviors, treatment adherence, and use of support and health services could impact aspects of physical and mental health such as immune function and psychiatric symptoms. Prior work published by the investigators reported poor CD-4 count association with poor ART adherence and MDD, which persists where MDD is untreated. ${ }^{5}$ Faith beliefs could be assessed to help improve adherence and psychiatric symptom treatment. Future research goals could include prospective examination to serially measure spiritual or religious practices, spiritual advisor visits, and the relationship between spiritual interventions and mental/physical health outcomes.

\section{Conclusion}

Assessment of and addressing spiritual or religious beliefs could be beneficial to HIV+ individuals; more so if a chronic mental disorder such as depression has also been identified. Health care providers should screen and treat depression in this patient population as well as collaborate with other health and spiritual care providers to identify and address spiritual needs to optimize health outcomes. Also, important is an understanding of beliefs, behaviors, and medication use processes that contribute to MRPs and non-adherence. More research is warranted to understand the role of spirituality in mental health and medication adherence in chronic conditions. 


\section{Acknowledgments}

This work was supported by pilot funds awarded to Dr. Oji through a grant from the National Institutes of Mental Health (NIMH) R25MH08066 and in part from the National Institutes of Health (NIH) Contract No. HH5N261200800001E awarded to Dr Evaristus Nwulia. The content is solely the responsibility of the authors and does not necessarily represent the official views or policies of the NIMH or NIH Department of Health and Human Services. The contributions of Dr Suad Kapetanovic, MD, University of Southern California; Dr Patricia Noumedem, PharmD, Howard University; also FMCS staff, especially James Perry, CACI, are appreciated.

\section{Disclosure}

The authors report no conflicts of interest in this work.

\section{References}

1. Oji V. Mind, medications \& mental disorders: a spiritual approach. J Christ Nurs. 2010;27(2):76-83.

2. patheos.com [ homepage on the Internet]. Patheos. Faith, Spirituality, Belief, Religion... What's the Difference? [May 5, 2014]. Available from: http://www.patheos.com/blogs/faithonthecouch/2014/05/faith-spiritualitybelief-religion-whats-the-difference/. Accessed March 8, 2017.

3. Mohr WK. Spiritual issues in psychiatric care. Perspect Psychiatr Care. 2006;42(3):174-183.

4. Woltmann E, Grogan-Kaylor A, Perron B Georges H, Kilbourne AM, Bauer MS. Comparative effectiveness of collaborative chronic care models for mental health conditions across primary, specialty and behavioral health care settings: systematic review and meta-analysis. Am J Psychiatry. 2012;169(8):790-804.

5. Amanor-Boadu S, Hipolito, MS, Rai N, et al. Poor CD4 count is a predictor of untreated depression in human immunodeficiency virus-positive African-Americans. World J Psychiatry. 2016;6(1): $128-135$.

6. Owe-Larsson B, Sall L, Salamon E, Allgulander C. HIV+ infection and psychiatric illness. Afr J Psychiatry (Johnannesbg). 2009; 12(2):115-128.

7. Berger-Greenstein JA, Cuevas CA, Brady SM, Trezza G, Richardson MA, Keanne TM. Major depression in patients with HIV+/ AISDS and substance abuse. AIDS Patient Care STDS. 2007;21(12): 942-955.

8. Evans DL, Ten Have TR, Douglas SD, et al. Association of depression with viral load, CD8 T lymphocytes, and natural killer cells in women with HIV+ infection. Am J Psychiatry. 2002;159(10):1752-1759.

9. Morrison MF, Petitto JM, Ten Have T, et al. Depressive and anxiety disorders in women with HIV+ infection. Am J Psychiatry. 2002; 159(5):789-796.

10. Bing EG, Burnam MA, Longshore D, et al. Psychiatric disorders and drug use among human immunodeficiency virus-infected adults in the United States. Arch Gen Psychiatry. 2001;58(8):721-728.

11. Johnson JG, Rabkin JG, Lipsitz JD, Williams JB, Remien RH. Recurrent major depressive disorder among human immunodeficiency virus (HIV+)-positive and HIV+-negative intravenous drug users: findings of a 3-year longitudinal study. Compr Psychiatry. 1999;40(1):31-34.

12. Watkins CC, Pieper AA, Triesman GJ. Safety considerations in drug treatment of depression in HIV+-positive patients: an updated review. Drug Saf. 2011;34(8):623-639.

13. Kapetanovic S, Christensen S, Karim R, et al. Correlates of perinatal depression in HIV+-infected women. AIDS Patient Care STDS. 2009;23(2):101-108.
14. Levine AJ, Singer EJ, Sinsheimer JS, et al. CCL3 genotype and current depression increase risk of HIV+-associated dementia. Neurobehav HIV + Med. 2009;1:1-7.

15. Dube B, Benton T, Cruess DG, Evans DL. Neuropsychiatric manifestations of HIV+ infection and AIDS. J Psychiatry Neurosci. 2005;30(4): 237-246.

16. Atkinson MJ, Petrozzino JJ. An evidence-based review of treatmentrelated determinants of patients' nonadherence to HIV+ medications. AIDS Patient Care STDS. 2009;23(11):903-914.

17. D.C. Department of Health [homepage on the Internet] HIV+/AIDS, Hepatitis, STD, and TB Administration Annual Epidemiology and Surveillance Report 2013; D.C. Department of Health. Available from: www.doh.dc.gov/hahsta. Accessed March 8, 2017.

18. MacLean CD, Susi B, MD, Phifer N, et al. Patient reference for physician discussion and practice of spirituality. J Gen Intern Med. 2003; 18(1):38-43.

19. Kasen S, Wickramaratne P, Gameroff MJ, Weissman MM. Religiosity and resilience in persons at high risk for major depression. Psychol Med. 2012;42(3):509-519.

20. Park J, Hong JP, Park S, Cho M. The relationship between religion and mental disorders in a Korean population. Psychiatry Investig. 2012; 9(1):29-35.

21. Miller L, Bansal R, Wickramaratne P, Hao X, Tenke CE, Weissman MM, Peterson BS. Neuroanatomical correlates of religiosity and spirituality: a study in adults at high and low familial risk for depression. JAMA Psychiatry. 2014;71(2):128-135.

22. Meredith KL, Jeffe DB, Mundy LM, Fraser VJ. Sources influencing patients in their HIV+ medication decisions. Health Educ Behav. 2001; 28(1):40-50.

23. Astrow AB, Puchalski CM, Sulmasy DP. Religion, spirituality, and health care: social, ethical, and practical considerations. Am J Med. 2001;110(4):283-287.

24. Pence BW, Gaynes BN, Whetten K, Eron JJ Jr, Ryder RW, Miller WC. Validation of a brief screening instrument for substance abuse and mental illness in HIV+-positive patients. J Acquir Immune Defic Syndr. 2005;40(4):434-444.

25. Dalmida SG, Koenig HG, Holstad MM, Wirani MM. The psychological well-being of people living with HIV+/AIDS and the role of religious coping and social support. Int J Psychiatry Med. 2013;46(1):57-83.

26. Park J, Nachman S. The link between religion and HAART adherence in pediatric HIV+ patients. AIDS Care. 2010;22(5):556-561.

27. Vyavaharkar M, Moneyham L, Tavakoli A, Phillips KD, Murdaugh C, Jackson K, Meding G. Social support, coping, and medication adherence among HIV+-positive women with depression living in rural areas of the southeastern United States. AIDS Patient Care STDS. 2007; 21(9):667-680.

28. Powell-Cope GM, White J, Henkelman EJ, Turner BJ. Qualitative and quantitative assessments of HAART adherence of substance-abusing women. AIDS Care. 2003;15(2):239-249.

29. Haubrich RH, Little SJ, Currier JS. The value of patient-reported adherence to antiretroviral therapy and immunologic response. California Collaborative Treatment Group. AIDS. 1999;13(9):1099-1107.

30. Patterson DL, Swindells S, Mohr J, et al. Adherence to protease inhibitor therapy and outcomes in patients with HIV+ infection. Ann Intern Med. 2000;133(1):21-30.

31. DeGrezia MG. Exploration of Coping Strategies in Older, Community Dwelling, HIV + Positive Individuals in Baltimore [dissertation]. Baltimore: University of Maryland; 2012.

32. McIntosh RC, Rosselli M. Stress and coping in women living with HIV+: a meta-analytic review. AIDS Behav. 2012;16(8):2144-2159.

33. Kremer H, Ironson G, Porr M. Spiritual and mind-body beliefs as barriers and motivators to HIV+-treatment decision-making and medication adherence? A qualitative study. AIDS Patient Care STDS. 2009; 23(2):127-134.

34. Martinez J, Lemos D, Hosek S; Adolescent Medicine Trials Network. Stressors and sources of support: the perceptions and experiences of newly diagnosed Latino youth living with HIV+. AIDS Patient Care STDS. 2012;26(5):281-290. 
35. Mahmoudi M, Dehdari T, Shojaeezadeh D, Abbasian L. Coping with stress strategies in HIV+-infected Iranian patients. J Assoc Nurses AIDS Care. 2015;26(4):464-471.

36. Lorenc A, Robinson N. A review of the use of complementary and alternative medicine and HIV+: issues for patient care. AIDS Patient Care STDS. 2013;27(9):503-510.

37. Audu B, Morgan R, Rutter P. Qualitative exploration of the relationship between HIV+/AIDS patients' experiences of clinical services and treatment adherence at Maitama District Hospital, Abuja, Nigeria. AIDS Care. 2014;26(2):270-273.

38. Mutumba M, Bauermeister JA, Musiime V, et al. Psychosocial challenges and strategies for coping with HIV+ among adolescents in Uganda: a qualitative study. AIDS Patient Care STDS. 2015;29(2):86-94.

39. Wells KB, Jones L, Chung B, et al. Community-partnered clusterrandomized comparative effectiveness trial of community engagement and planning or resources for services to address depression disparities. J Gen Intern Med. 2013;28(10):1268-1278.

40. Simoni JM, Frick PA, Huang B. A longitudinal evaluation of a social support model of medication adherence among HIV+-positive men and women on antiretroviral therapy. Health Psychol. 2006;25(1): 74-81.

41. Russell CK, Bunting SM, Graney M, Hartig MT, Kisner P, Brown B. Factors that influence the medication decision making of persons with HIV+/AIDS: a taxonomic exploration. JAssoc Nurses AIDS Care. 2003 14(4):46-60.

42. Nozaki I, Kuriyama M, Manyepa P, Zyambo MK, Kakimoto K, Bärnighausen T. False beliefs about ART effectiveness, side effects and the consequences of non-retention and non-adherence among ART patients in Livingstone, Zambia. AIDS Behav. 2013;17(1):122-126.

43. Ironson G, Kremer H. Spiritual transformation, psychological wellbeing, health, and survival in people with HIV+. Int J Psychiatry Med. 2009;39(3):263-281.

44. Beland A. The effect of spirituality and social factors on depression and anxiety in an elderly retirement home population [dissertation]. Fresno: Alliant International University; 2005.

45. Aspeling HE, van Wyk NC. Factors associated with adherence to antiretroviral therapy for the treatment of HIV+-infected women attending an urban care facility. Int J Nurs Pract. 2008;14(1):3-10.

46. Asgary R, Antony S, Grigoryan Z, Aronson J. Community perception, misconception, and discord regarding prevention and treatment of infection with human immunodeficiency virus in Addis Ababa, Ethiopia. Am J Trop Med Hyg. 2014;90(1):153-159.

47. Badahdah AM, Pedersen DE. "I want to stand on my own legs": a qualitative study of antiretroviral therapy adherence among HIV+-positive women in Egypt. AIDS Care. 2011;23(6):700-704.
48. Musheke M, Bond V, Merten S. Individual and contextual factors influencing patient attrition from antiretroviral therapy care in an urban community of Lusaka, Zambia. J Int AIDS Soc. 2012;15 Suppl 1:1-9.

49. Watt MH, Maman S, Jacobson M, Laiser J, John M. Missed opportunities for religious organizations to support people living with HIV+/AIDS: findings from Tanzania. AIDS Patient Care STDS. 2009;23(5):389-394.

50. Nyamathi A, Ekstrand M, Salem BE, Sinha S, Ganguly KK, Leake B. Impact of Asha intervention on stigma among rural Indian women with AIDS. West J Nurs Res. 2013;35(7):867-883.

51. Martin SS. Illness of the mind or illness of the spirit? Mental healthrelated conceptualization and practices of older Iranian immigrants. Health Soc Work. 2009;34(2):117-126.

52. Curioso WH, Kepka D, Cabello R, Segura P, Kurth AE. Understanding the facilitators and barriers of antiretroviral adherence in Peru: a qualitative study. BMC Public Health. 2010;10:13.

53. Huguelet P, Mohr S, Borras L, Gillieron C, Brandt PY. Spirituality and religious practices among outpatients with schizophrenia and their clinicians. Psychiatr Serv. 2006;57(3):366-372.

54. Murray-Swank AB, Lucksted A, Medoff DR, Yany Y, Wohlheiter MS, Dixon LB. Religiosity, psychosocial adjustment, and subjective burden of persons who care for those with mental illness. Psychiatr Serv. 2006;57(3):361-365.

55. Koenig HG. Faith and mental health: religious resources for healing. Philadelphia: Templeton; 2005.

56. Koenig HG. Religion and mental health: a review of previous research. Paper presented at: Summer Research Workshop on Spirituality and Health; August; 2009; Durham, NC.

57. Koenig HG, Larson DB, Larson SS. Religion and coping with serious mental illness. Ann Pharmacother. 2001;35(3):352-359.

58. Larson DB, Sherrill KA, Lyons JS, et al. Dimensions and valences of measures of religious commitment found in the American Journal of Psychiatry and the ArcHIV+es of General Psychiatry, 1978-1989. Am J Psychiatry. 1992;149:557-559.

59. Dolittle BR, Farrell M. The association between spirituality and depression in an urban clinic. Prim Care Companion J Clin Psychiatry. 2004; 6(3):114-118.

60. Cotton S, Puchalski CM, Sherman SN, et al. Spirituality and religion in people with HIV+/AIDS. J Gen Intern Med. 2006; 21 Suppl 5:S5-S13.

61. Bangsberg DR, Moss AR, Deeks SG. Paradoxes of adherence and drug resistance to HIV+ antiretroviral therapy. J Antimicrob Chemother. 2004;53(5):696-699.

62. Underwood LG, Teresi JA. The daily spiritual experience scale: development, theoretical description, reliability, exploratory factor analysis, and preliminary construct validity using health related data. Ann Behav Med. 2002;24(1):22-33.
HIV/AIDS - Research and Palliative Care

\section{Publish your work in this journal}

HIV/AIDS - Research and Palliative Care is an international, peerreviewed open access journal focusing on advances in research in HIV its clinical progression and management options including antiviral treatment, palliative care and public healthcare policies to control viral spread. The journal is included in PubMed. The manuscript man-
Dovepress

agement system is completely online and includes a very quick and fair peer-review system, which is all easy to use. Visit http://www.dovepress. com/testimonials.php to read real quotes from published authors. 